\title{
Novel TaqMan PCR screening methods for element cry3A and construct gat/T-pinII to support detection of both known and unknown GMOs
}

\author{
Theo W. Prins ${ }^{1} \cdot$ Richard A. van Hoof $^{1} \cdot$ Ingrid M. J. Scholtens $^{1} \cdot$ Esther J. Kok $^{1}$
}

Received: 9 May 2016 / Revised: 27 June 2016 / Accepted: 16 July 2016 / Published online: 2 August 2016

(C) The Author(s) 2016. This article is published with open access at Springerlink.com

\begin{abstract}
The import and use of genetically modified organisms (GMOs) is strictly regulated in the European Union. In order to maintain the legislation on GMOs, a genetic element screening is generally applied as a first step to detect authorised as well as unauthorised GMOs. Subsequent identification of GMOs that relate to the detected elements is performed by the application of event-specific detection methods. However, as the diversity of GMOs on the world market is increasing, there is an ongoing need for methods for additional informative screening elements. Genes that are increasingly applied in GMOs are cry $3 A$ (including variants $m c r y 3 A$ and $e C r y 3.1 A b$ ) conferring resistance to Bt toxins, and gat, detoxifying glyphosate. Novel TaqMan PCR detection methods for element cry3A and construct gat/T-pinII were developed to support the identification of maize MIR604, 98140, 5307, canola 61061 and 73496, and soybean 356043. Also, other unknown (unauthorised) GMOs containing cry $3 A$ and/or gat/T-pinII can potentially be detected. Specificity, efficiency and sensitivity of the methods were evaluated.
\end{abstract}

Keywords Screening $\cdot$ qPCR $\cdot$ Real-time $\cdot$ PCR . Detection · Identification

Theo W. Prins

theo.prins@wur.nl

Richard A. van Hoof

richard.vanhoof@wur.nl

Ingrid M. J. Scholtens

ingrid.scholtens@wur.nl

Esther J. Kok

esther.kok@wur.nl

1 RIKILT Wageningen UR, Akkermaalsbos 2, 6708

WB Wageningen, Netherlands

\section{Introduction}

In the European Union (EU), the import and use of genetically modified organisms (GMOs) is strictly regulated. Currently, March 2016, 66 GM crop plant varieties are authorised in the EU $(10 \times$ cotton, $37 \times$ maize, $6 \times$ canola, $12 \times$ soybean and $1 \times$ sugar beet) [19]. EU-authorised GMOs and derived materials have to be labelled as such [19]. Some additional rules apply for GMO-derived feed materials. Under Regulation (EC) No 619/2011 (European [17], GMOs that are in the process of being authorised (currently $20 \mathrm{GM}$ plants) are allowed up to $0.1 \%$ in feed if they have already been authorised in another country and if reference material and a detection method are available. When a product or ingredient is not labelled as GMOderived, EU-authorised GMOs are allowed to be present in the ingredient up to $0.9 \%$, if this presence is unintended and cannot be technically avoided. Some GMOs that are withdrawn from the market or where the market approval has expired are allowed up to $0.1 \%$ in feed (European Commission, [17-19]. All other GMOs are not authorised for the EU market (0\% tolerance).

Specific detection methods are needed for enforcement of these labelling requirements. TaqMan detection methods that target the authorised GM events are delivered by the respective applicants, verified by the European Union Reference Laboratory for Genetically Modified Food and Feed (EURL-GMFF) and interlaboratory validated by the EURL-GMFF together with the European Network of GMO Laboratories (ENGL) [7]. Specific targets for detection strategies are GMO-related genetic elements (coding sequences (CS-), promoters (P-) or terminators (T-)), constructs (the junction sequences bridging adjacent elements) and events (area spanning the $5^{\prime}$ or $3^{\prime}$ insertion site and the flanking plant region). Because already many GMOs are 
allowed on the EU market, screening strategies targeting GMO elements and constructs are applied to limit the number of event-specific methods that need to be performed $[14,37,43]$. Also, pre-spotted screening and event plates have been developed $[34,36]$ to facilitate the screening and identification of GMOs in food and feed products.

Depending on the type of samples to be tested, more or fewer elements and constructs can be selected for screening. Screening with, for example, five detection methods as described by Waiblinger et al. [43] would be a good option to cover the majority of known GMOs in samples for which the absence of known GMOs has to be confirmed. For samples that are labelled as GMO and that may contain several different GMOs (e.g. feed), an extended element and construct screening can be more informative, as here the focus will be primarily on the detection and identification of unauthorised GMOs [13, 37]. If specific detected elements cannot be explained by the subsequently identified events, this can be an indication for the presence of unauthorised GMOs in the sample. The EUginius GMO database (www.euginius.eu) provides an analysis tool that can aid the analyses based on the GMO elements that have been identified and those that have been found negative in the screening. The JRC GMO-Matrix event finder [1] provides a comparable identification strategy. Screening strategies are also described in a CEN Technical Standard NPR-CEN/TS 16707:2014 en [12], and a review on this subject has been written by Fraiture et al. [20].

Where the detection of promoter P-35S from Cauliflower mosaic virus (CaMV) or terminator T-nos from Rhizobium radiobacter was once sufficient to detect most authorised GMOs, there now is a tendency to use a wide variety of promoters, coding genes and terminators in more recent GMOs. Also, the use of plant-derived GMO elements requires the use of construct-specific methods instead of element-specific methods to avoid false positives in feed samples containing multiple species. Therefore, additional detection methods are sometimes necessary in order to target specific (groups of) GMOs. Some recent examples of additional qPCR screening methods are the element bar and construct ctp2/cp4epsps [21], the elements cry1A.105 and cry2Ab2 [15], promoters P-FMV, P-nos, P-SSuAra, P-TA29, P-ubi, P-rice actin and terminators T-35S, T-E9, T-ocs, T- $g$ 7 [14], element vip3A [29], and element crylAb/Ac and construct P-ubi/cry [22]. Recent examples of $\mathrm{SYBR}^{\circledR}$ Green detection methods are P-nos and P-FMV [9], cry3Bb and gat/T-pinII [10], and the application of Combinatory SYBR ${ }^{\circledR}$ Green PCR Screening (CoSYPS) [4, 30, 42]. Detection and identification of GMOs is not static. Progressive insight, changes in GMO authorisations, development of novel GMOs with sometimes (plant-derived) elements for which no suitable detection methods are available, regularly require adjusted adequate detection strategies. Nevertheless, there are still GMOs for which no suitable screening elements are available.

Here, we describe the development of TaqMan PCR detection methods for the coding sequence cry $3 A$ and the construct gat/T-pinII to facilitate the detection of present and future GMOs containing these elements. The element cry $3 A$ and construct gat/T-pinII were selected as targets since they are present in GMOs that harbour zero or one element that can be detected in the element screening, which is not sufficient for the identification of the GMO(s) present. The cry $3 A$ method was initially intended for the screening for MIR604 maize (SYN-IR6Ø4-5) and 5307 maize (SYN-Ø53Ø7-1), but may also detect other GMOs containing cry $3 A$. At least 27 potato events that are deregulated in the USA [2], the Russian 2904/1 kgs (ISAAA's GM Approval Database [24]), a GM potato developed in Bulgaria [26] and two GM potatoes developed in China $[23,31]$ contain cry $3 A$ or variants thereof. For other GMOs like the currently unauthorised MZIR098 (SYN-ØØØ98-3) containing ecry3.1Ab (chimaera of $m C r y 3 A$ and $c r y l A b$ ), the $\operatorname{cry} 3 A$ detection method may be suitable, although this GMO also contains the CaMV 35S promoter and the nos terminator that will already be used in most screening approaches. Also, in experimental lines of tobacco [35], poplar [16], alfalfa [41], Norway spruce [8] and rice [27], cry $3 A$ was applied, conferring resistance against Coleoptera. The gat/T-pinII method can be used to screen for canola 61061 (DP-Ø61Ø61-7) and 73496 (DP-Ø73496-4), maize 98140 (DP-Ø9814Ø-6) for which events no GMO element screening methods are available yet, and soybean 356043 (DP-356Ø43-5) that can be screened for only using the promoter element P-35S. In the present paper, we describe the newly developed methods and evaluate these in the light of established ENGL method performance requirements [25].

\section{Materials and methods}

\section{Samples}

MIR604 and Event 5307 were used as positive reference materials for the cry $3 A$ detection method. A range of GMOs (including those containing variants of the cry gene) were used as negative control. For the construct gat/TpinII, maize 98140 and soybean 356043 were used as positive controls. A range of GMOs (including those containing either gat or pinII) were used as negative control. In Table 1, all reference materials are described. 
Table 1 GMO reference materials obtained from the ERM (European Reference Materials: IRMM, Geel, Belgium) or AOCS (American Oil Chemist's Society: Urbana, IL, USA)

\begin{tabular}{|c|c|c|c|c|c|}
\hline Crop & GMO & Reference & Potential target(s) cry/gat/T-pinII & $\operatorname{cry} 3 A$ & gat/T-pinIl \\
\hline \multirow[t]{15}{*}{ Soybean } & A2704-12 & AOCS 0707-B $100 \%$ & & - & - \\
\hline & A5547-127 & AOCS 0707-C $100 \%$ & & - & - \\
\hline & CV127 & AOCS 0911-C > $96.32 \%$ & & - & - \\
\hline & DAS44406 & ERM-BF436e $10 \%$ & & - & - \\
\hline & DAS68416 & ERM-BF432d $10 \%$ & & - & - \\
\hline & DAS81419 & ERM-BF437e $10 \%$ & & - & - \\
\hline & DP305423 & ERM-BF426d $10 \%$ & & - & - \\
\hline & DP356043 & ERM-BF425d $10 \%$ & CS-gat4601, T-pinII & - & + \\
\hline & FG72 & AOCS 0610-A2 $100 \%$ & & - & - \\
\hline & GTS40-3-2 & ERM-BF410f $5 \%$ & & - & - \\
\hline & MON87701 & AOCS 0809-A $100 \%$ & CS-crylAc & - & - \\
\hline & MON87705 & AOCS $0210-\mathrm{A}>99.4 \%$ & & - & - \\
\hline & MON87708 & AOCS 0311-A $100 \%$ & & - & - \\
\hline & MON87769 & AOCS 0809-B $100 \%$ & & - & - \\
\hline & MON89788 & AOCS 0906-B > $99.4 \%$ & & - & - \\
\hline \multirow[t]{20}{*}{ Maize } & Event 3272 & ERM-BF420c $9.8 \%$ & & - & - \\
\hline & 5307 & AOCS 0411-D > 99.88\% & CS-ecry3.1Ab & + & - \\
\hline & Bt11 & ERM-BF412f $4.89 \%$ & $\mathrm{CS}-\operatorname{cry} 1 A b$ & - & - \\
\hline & Bt176 & ERM-BF411f $5 \%$ & CS-crylAb & - & - \\
\hline & DAS40278 & ERM-BF433d $10 \%$ & & - & - \\
\hline & DAS59122 & ERM-BF424d $9.87 \%$ & $\begin{array}{l}\text { CS-cry34Ab1, } \\
\text { CS-cry35Ab1, T-pinII }\end{array}$ & - & - \\
\hline & 98140 & ERM-BF427d $10 \%$ & CS-gat4621, T-pinII & - & + \\
\hline & 1981 & ERM-BF438e $10 \%$ & & - & - \\
\hline & 4114 & ERM-BF439b > $98.6 \%$ & $\begin{array}{l}\text { CS-cry } 34 A b 1, \\
\text { CS-cry } 35 A b 1, \\
\text { T-pinII, CS-cry } 1 F\end{array}$ & - & - \\
\hline & GA21 & ERM-BF414f $4.29 \%$ & & - & - \\
\hline & MIR162 & AOCS $1208 \mathrm{~A}>99.98 \%$ & CS-vip $3 A a 20$ & - & - \\
\hline & MIR604 & ERM-BF423d $9.85 \%$ & CS-cry $3 A$ & + & - \\
\hline & MON810 & ERM-BF413f $5 \%$ & $\mathrm{CS}$ - $\operatorname{cry} 1 \mathrm{Ab}$ & - & - \\
\hline & MON863 & ERM-BF416d $9.85 \%$ & CS-cry $3 B b 1$ & - & - \\
\hline & MON87427 & AOCS 0512-A > $99.94 \%$ & & - & - \\
\hline & MON87460 & AOCS 0709-A > 99.05\% & & - & - \\
\hline & MON88017 & AOCS 0406-D > 99.05\% & CS-cry $3 B b 1$ & - & - \\
\hline & MON89034 & AOCS 0906-E > $99.42 \%$ & $\begin{array}{l}\text { CS-cry1A.105, } \\
\text { CS-cry } 2 A b 2\end{array}$ & - & - \\
\hline & NK603 & ERM-BF415f $4.91 \%$ & & - & - \\
\hline & TC1507 & ERM-BF418d $9.86 \%$ & $\mathrm{CS}$-cry $1 F a 2$ & - & - \\
\hline \multirow[t]{3}{*}{ Canola } & 73496 & ERM-BF434e $10 \%$ & CS-gat4621, T-pinII & - & + \\
\hline & MON88302 & AOCS 1011-A > $99.94 \%$ & & - & - \\
\hline & Topas $19 / 2$ & AOCS 0711-D $100 \%$ & & - & - \\
\hline \multirow[t]{6}{*}{ Cotton } & $281-24-236 * 3006-210-23$ & ERM-BF422d $10 \%$ & CS-cry $1 F a 2$, CS-cry $1 A c$ & - & - \\
\hline & GHB119 & ERM-BF428c $10 \%$ & CS-cry $2 A e$ & - & - \\
\hline & GHB614 & AOCS $1108-A 4>99.99 \%$ & & - & - \\
\hline & MON1445 & AOCS 0804-B > $99.4 \%$ & & - & - \\
\hline & MON15985 & AOCS 0804-D > 98.45\% & CS-cry $1 A c$, CS-cry $2 A b 2$ & - & - \\
\hline & MON531 & AOCS $0804-C>97.39 \%$ & CS-cry $1 A c$ & - & - \\
\hline
\end{tabular}


Table 1 continued

\begin{tabular}{|c|c|c|c|c|c|}
\hline Crop & GMO & Reference & Potential target(s) cry/gat/T-pinII & $\operatorname{cry} 3 A$ & gat/T-pinIl \\
\hline & MON88913 & AOCS 0906-D & & - & - \\
\hline & T304-40 & ERM-BF429c $10 \%$ & CS-crylAb & - & - \\
\hline Potato & EH92-527-1 & ERM-BF421b $100 \%$ & P-pinII, CS-pinII, T-pinII & - & - \\
\hline Tomato & Wild type & Solanum lycopersicum & P-pinII, CS-pinII, T-pinII & - & - \\
\hline
\end{tabular}

Targets and non-targets that could cross-react (like cry-genes for cry $3 A$ ) are depicted. The last two columns give the result of the specificity testing where ' + ' is detected and ' - ' is not detected. $C S$ coding sequence, $T$ terminator

\section{DNA extraction}

DNA from reference material was isolated from $100 \mathrm{mg}$ material using a CTAB DNA isolation method [33], the Maxwell ${ }^{\circledR} 16$ Tissue DNA Purification Kit (Promega) used with the Maxwell ${ }^{\circledR} 16$ machine (Promega), or with CTAB/Qiagen (CTAB lysis step, followed by the DNeasy Plant Mini Kit (Qiagen) isolation. Optical density was measured on a Nanodrop spectrophotometer (ND-1000, Montchanin, DE, USA), which was used to quantify and assess the purity of the DNA. DNAs (extracted from reference materials, or provided as DNA) were diluted with water (Gibco distilled water, DNase/RNase free, Life Technologies, Grand Island NY, USA) to $10 \mathrm{ng} / \mu \mathrm{l}$ final concentration and stored at $4{ }^{\circ} \mathrm{C}$, or at $-20{ }^{\circ} \mathrm{C}$ for longterm storage.

\section{Primers and probes}

Primers and probe for $\operatorname{cry} 3 A$ were designed using Beacon Designer 7.0 (PREMIER Biosoft, Palo Alto, CA, USA). Settings for the amplicons were $\mathrm{Ta}=60{ }^{\circ} \mathrm{C} \pm 2{ }^{\circ} \mathrm{C}$; amplicon length 70-120 bp (base pairs).

Primers and probe for gat/T-pinII were designed using Beacon Designer 8.14 (PREMIER Biosoft, Palo Alto, CA, USA). Settings for the amplicons were $\mathrm{Ta}=60{ }^{\circ} \mathrm{C} \pm 5^{\circ} \mathrm{C}$; amplicon length $60-120 \mathrm{bp}$. The detection method was partially based on the SYBR Green qPCR CoSYPS method described by Broeders et al. [10]. Primers and probes were synthesised by Biolegio (Nijmegen, Netherlands) with a high-purity method. Probes were purified by HPLC.

Sequence analysis was performed at the GenBank database by using the BLASTn tool (Basic Local Alignment Search Tools Nucleotide) of the National Center for Biotechnology Information (NCBI). The alignments among similar sequences were performed by using the software Clustal Omega [38] version 1.2.1.

\section{Mastermix and PCR programme}

The following mastermix was used in $25-\mu l$ final volume: $1 \times$ Diagenode mastermix with UNG (Diagenode,
Belgium) to prevent amplification of previously amplified products, $400 \mathrm{nM}$ forward and reverse primer each, $200 \mathrm{nM}$ probe, $5 \mu \mathrm{l}$ water, $5 \mu \mathrm{l}$ DNA (10 $\mathrm{ng} / \mu \mathrm{l}$, or dilutions thereof). PCR programme in Bio-Rad CFX96: initial decontamination with UNG (uracil-N-glycosylase) $120 \mathrm{~s}$ at $50{ }^{\circ} \mathrm{C}$, denaturation and activation $600 \mathrm{~s}$ at $95^{\circ} \mathrm{C}$, then 45 cycles with $15 \mathrm{~s}$ at $95{ }^{\circ} \mathrm{C}, 60 \mathrm{~s}$ at $60{ }^{\circ} \mathrm{C}$ (hold at $20^{\circ} \mathrm{C}$ indefinitely). qPCR trace files were analysed with the Bio-Rad CFX manager software version 3.1.

\section{Limit of detection and PCR efficiency}

Limit of detection and PCR efficiency were determined according to the minimum performance requirements for analytical methods of GMO testing [25] and the guidelines published by Broeders et al. [11]. The detection limit should at least be 20 haploid genome copies. The TaqMan PCR analysis was evaluated for each primer/probe pair by the serial dilution of CRM for and in water. MIR604 maize was used for cry3A. DP073496 canola and DP356043 soybean were used for gat/T-pinII. The copy numbers in the calibration curve samples are obtained by dividing the amount of sample DNA (picograms) by the published average $1 C$ value for the maize $(2.725 \mathrm{pg})$, canola $(1.15 \mathrm{pg})$ and soybean $(1.13 \mathrm{pg})$ nuclear genome [3].

\section{Results and discussion}

\section{TaqMan PCR development}

The cry3A gene (BCH abbreviation CS-cry3A-BACTU) is derived from Bacillus thuringiensis subsp. tenebrionis, strain BI 256-82. It codes for a Bt-toxin, conferring resistance to Western corn rootworm (Diabrotica virgifera virgifera), Northern corn rootworm (D. longicornis barberi) and other related Coleopteran species [5]. The gene is often codon-optimised [40] for the target species (mcry3A), or fused to cry $1 \mathrm{Ab}(\mathrm{eCry} 3.1 \mathrm{Ab})$. At least 30 known potato events contain cry $3 A$ or variants thereof. For cry $3 A$ in potato, a conventional PCR detection method was already developed [39], but to reduce chances of contamination, 
Table 2 Primers and probe designed for the detection of element CS-cry3A and construct gat/T-pinII

\begin{tabular}{lllll}
\hline Target & Name & Sequence 5'-3' & Amplicon size (bp) & Reference \\
\hline cry3A & cry3A-F & CAGCAACATCGAGAACTA & 117 & MIR604 (GenBank DJ437707.1) \\
& cry3A-R & CTCCAGTAGTTGAAGCTG & & 5307 (GenBank GU327680.1) \\
& cry3A-P & FAM-TGTTCGACTACCTGCACCGC-BHQ1 & & 356043 (GenBank FB741980.1) \\
gat/T-pinII & gat/T-pinII-F & GGACCTCACATCCTGATGTATAA & 111 & \\
& gat/T-pinII-R & GCATCCTTTTATTTCATACATTA & & \\
& gat/T-pinII-P & FAM-CCATCTTCTGGATTGGCCAACTTAA-BHQ1 & & \\
\hline
\end{tabular}

Table 3 CLUSTAL Omega (1.2.1) multiple sequence alignment with $9100 \%$ identical amplicon entries A (represented by 98140: KP784699, containing gat/T-pinII) and $8100 \%$ identical amplicon

FW-probe-Rev GGACCTCACATCCTGATGTATAA

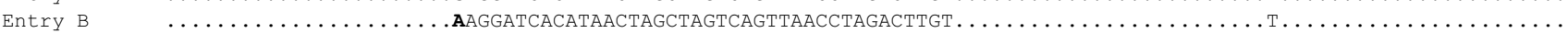

Dots represent identity with the primers and probe binding sites

qPCR in closed vials is preferred. A loop-mediated isothermal amplification (LAMP) assay for detection of cry3A is also available [28], but for applicability in a TaqMan PCR screening strategy, this is not suitable. The gene is also applied in experimental lines of GM tobacco, poplar, alfalfa, Norway spruce and rice, and maize Event 5307, MIR604 and MZIR098. The latter one is currently pending for the determination of non-regulated status in the USA [2].

The construct gat/T-pinII is a synthetic fusion sequence between the coding sequence of the glyphosate- $\mathrm{N}$-acetyltransferase ( $g a t)$ gene and the terminator from the proteinase inhibitor II (pinII) gene. The gat gene (CS-gatBACLI) is derived from Bacillus licheniformis. It codes for glyphosate-N-acetyltransferase, which is able to detoxify glyphosate [6]. There are at least two modified genes present in known GMOs: GAT4621 and GAT4601. The pinII terminator (T-pinII-SOLTU) is derived from Solanum tuberosum [5]. The construct gat/T-pinII is at least present in canola 61061 and 73496, maize 98140 and soybean 356043.

Table 2 describes the primers and probes that were developed for the two TaqMan PCR detection methods, based on the GenBank entries in the reference.

\section{Specificity}

The specificity of the gat/T-pinII detection method was checked by similarity searches in silico by BLAST analysis against GenBank. BLASTn against the patent database with the gat/T-pinII amplicon from maize 98140 returned 17 different patents in the first 100 hits, of which 4 belonged to either canola 61061 and 73496 , or maize entries B (represented by patent WO2010077890, containing cry3A with one difference in the amplicon) shows the difference (at nt 24 in bold) between entries A and B

CCATCTTCTGGATTGGCCAACTTAA TAATGTATGAAATAAAAGGATGC
98140. The other hits were GMOs containing the gat/TpinII construct (Table 3). Patent US 8901377 is a patent on GM sunflower. The last eight patents showed a single difference in the amplicon, between the forward primer and the probe. This difference will not hinder a correct amplification of the amplicon.

BLASTn against the nucleotide collection (nr/nt) database with the gat/T-pinII amplicon from maize 98140 returned two entries (both maize 98140).

The specificity of the cry3A detection method was checked in silico by BLAST analysis against GenBank. BLASTn against the patent database with the cry $3 A$ amplicon from maize MIR604 returned eleven different patents in the first 100 hits, of which three belonged to either MIR604 or Event 5307. The other hits were GMOs containing the cry $3 A$ gene.

BLASTn against the nucleotide collection (nr/nt) database with the cry3A amplicon from maize MIR604 returned three entries. A CLUSTAL Omega multiple sequence alignment returned the alignment shown in Table 4. Amplicons for MIR604 and Event 5307 were included from the patent search.

The synthetic cry3A genes GenBank: JN989558.1 [32] and GenBank: M84650.1, and the two potato cry3A genes are not likely to be amplified with the designed primer combination. eCry3.1Ab (GenBank: GU327680.1) is the cry3A gene from Event 5307.

Summarising, the BLASTn analyses against $\mathrm{nr} / \mathrm{nt}$ and patent databases show that the element-specific method for $\operatorname{cry} 3 A$ is specific for $\operatorname{cry} 3 A$, and only returns hits with MIR604, Event 5307 and some other entries that contain $c r y 3 A$. BLASTn analyses against $\mathrm{nr} / \mathrm{nt}$ and patent databases show that the construct-specific method 
Table 4 CLUSTAL Omega (1.2.1) multiple sequence alignment of the cry $3 \mathrm{~A}$ amplicon

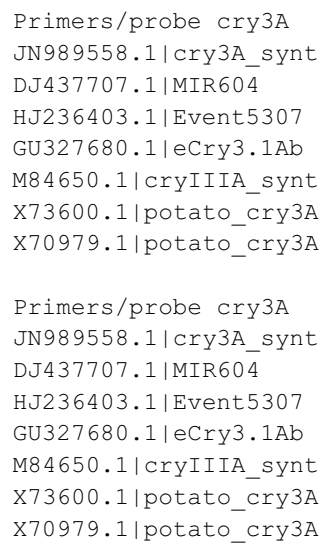

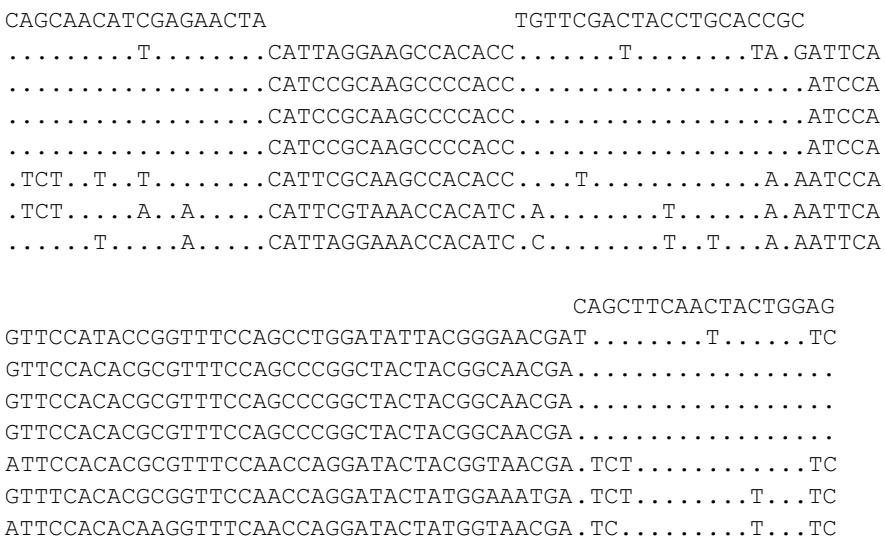

Dots represent identity with the primers and probe binding sites

for gat/T-pinII is specific for the gat/T-pinII construct, and only returns hits with canola 61061 (DP-Ø61Ø61-7) and 73496 (DP-Ø73496-4), and maize 98140 (DPØ9814Ø-6). No hit with soybean 356043 (DP-356Ø43-5) could be found that confirmed the entry as soybean 356043. Some other entries that contain gat/T-pinII were found, including a GM sunflower. One group of entries (all from Du Pont de Nemours and Company) from GenBank had one difference in the amplicon, without affecting its amplification.

Experimental results from testing the methods with nontarget transgenic events, non-transgenic material and target material showed that all reference materials described in Table 1 were negative for the cry3A detection method, except MIR 604 and Event 5307. For the construct-specific method gat/T-pinII, all reference materials described in Table 1 were negative for gat/T-pinII, except canola 73496 (50 ng $100 \%$ : $\mathrm{Cq}=23$ ), maize 98140 (50 ng $10 \%$ : $\mathrm{Cq}=28)$ and soybean $356043(50 \mathrm{ng} 10 \%: \mathrm{Cq}=30)$. Since the pinII terminator originates from S. tuberosum, both $S$. tuberosum and $S$. lycopersicum were tested as well. GMOs containing T-pinII (maize DAS59122 and 4114) were also included. All were found negative for the gat/TpinII construct-specific detection method. All results were in agreement with the expected outcome and confirmed the specificity of the two methods with the reference materials tested.

\section{Efficiency and correlation coefficient}

The efficiency and correlation coefficient $R^{2}$ were calculated with CFX software using five serial dilutions in duplicate (two reactions per concentration). In Table 5, the average values are given. Efficiency and $R^{2}$ are in accordance with ENGL minimum performance requirements that
Table 5 Average values for efficiency (\%) and $\mathrm{R}^{2}$ of the $\operatorname{cry} 3 A$ and gat/T-pinII detection methods

\begin{tabular}{llll}
\hline Method and target DNA & Efficiency (\%) & $\mathrm{R}^{2}$ & $\begin{array}{l}\text { DNA range } \\
\text { tested (ng) }\end{array}$ \\
\hline $\begin{array}{l}\text { cry3A with MIR604 maize } \\
\text { gat/T-pinII with 73496 }\end{array}$ & 102.3 & 0.9900 & $150-0.24$ \\
$\quad$ canola & 98.7 & 0.9964 & $150-1.20$ \\
$\begin{array}{l}\text { gat/T- } \text { pinII } \text { with } 356043 \\
\text { soybean }\end{array}$ & 101.0 & 0.9983 & $50-0.005$ \\
\hline
\end{tabular}

specify an efficiency range between 90 and $110 \%$ and an $R^{2}$ higher than or equal to 0.98 , in order for a PCR method to be used for quantification. The method performed in a linear quantitative manner in the full range DNA concentrations tested.

\section{Limit of detection}

For gat/T-pinII, a first estimate of the $\mathrm{LOD}_{10}$ (10 repeats of different copy levels where the LOD is at the amount of copies that were detected 10/10) was performed, ranging from 40 (10/10), 20 (10/10), 10 (10/10), 5 (7/10) and 1 copies $(6 / 10)$ per reaction in 10 repetitions (with 73496 canola and 356043 soybean). The estimated LOD $_{10}$ was below 10 copies. The 10 copies dilution was repeated 60 times to obtain an estimate of the $\mathrm{LOD}_{95} \%$. At 10 copies, $93 \%$ (57/60) of the reactions were positive. Next, 20 copies were repeated 60 times, resulting in 60/60 positives (100\%) for 73496 canola and 356043 soybean. The estimated LOD $95 \%$ is below 20 copies.

For $\operatorname{cry} 3 A$, the initial LOD estimation was performed with 10 reactions per concentration, ranging from 25 (10/10), $10(10 / 10), 5(9 / 10), 2.5(7 / 10)$ and 0.5 copies (2/10) (MIR604) per reaction. LOD $_{10}$ was below 10 copies. 
The 10 copies level was repeated 60 times to verify the $\mathrm{LOD}_{95} \%$ at 10 copies, resulting in 59/60 positives $(98.3 \%$ ). The estimated $\mathrm{LOD}_{95} \%$ is below 10 copies.

\section{Conclusion}

Two new methods were developed to improve the screening approach for known and unknown GMOs containing either the element cry $3 A$ or the construct gat/T-pinII. The cry3A detection method was specific for the cry $3 \mathrm{~A}$ element. No false positives were found with the $\operatorname{cry} 3 \mathrm{~A}$ detection method, including those GMOs containing cryrelated genes, and no false negatives were found since all the GMOs containing cry3A were positive. The gat/TpinII detection method was specific for the gat/T-pinII construct. No false positives and no false negatives were found with the gat/T-pinII detection method, because only the GMOs with gat4621/T-pinII and gat4601/T-pinII constructs were positive. Both methods were found satisfactory with regard to their specificity, PCR efficiency, linearity and sensitivity in the light of criteria for such methods as have been established by the European Network of GMO Laboratories. The applicability and practicability is expected to be similar as for other TaqMan screening methods. After full validation, the methods can be used in GMO element screening approaches to facilitate the detection and identification of maize 5307, MIR604 and 98140, soybean 356043, canola 73496 and potentially present currently unknown GMOs containing cry3A or gat/T-pinII.

Acknowledgments This research was funded by the Dutch government project WOT-02-004-005 'Validation and accreditation of detection methods for genetically modified organisms'.

\section{Compliance with ethical standards}

Conflict of interest The authors declare that they have no conflict of interest.

Compliance with ethics requirements This article does not contain any studies with animals performed by any of the authors.

Open Access This article is distributed under the terms of the Creative Commons Attribution 4.0 International License (http://creativecommons.org/licenses/by/4.0/), which permits unrestricted use, distribution, and reproduction in any medium, provided you give appropriate credit to the original author(s) and the source, provide a link to the Creative Commons license, and indicate if changes were made.

\section{References}

1. Angers-Loustau A, Petrillo M, Bonfini L, Gatto F, Rosa S, Patak A, Kreysa J (2014) JRC GMO-Matrix: a web application to support genetically modified organisms detection strategies. BMC Bioinform 15:1

2. APHIS-USDA (2016) Petitions of nonregulated status granted or pending by APHIS-USDA. http://www.aphis.usda.gov/brs/ not_reg.html. Accessed 16 March 2010

3. Arumuganathan K, Earle ED (1991) Nuclear DNA content of some important species. Plant Mol Biol Rep 9(3):208-218

4. Barbau-Piednoir E, Stragier P, Roosens N, Mazzara M, Savini C, Van den Eede G, Van den Bulcke M (2014) Inter-laboratory testing of GMO detection by combinatory SYBR ${ }^{\circledR}$ Green PCR Screening (CoSYPS). Food Anal Methods 7(8):1719-1728

5. BCH (2016a) BCH gene registry 14989 for cry3A. http://bch. cbd.int/database/record.shtml?documentid $=14989$. Accessed 16 March 2010

6. BCH (2016b) BCH gene registry 48363 for gat. http://bch.cbd. int/database/record.shtml?documentid $=48363$. Acessed 16 March 10

7. Bonfini L, Van den Bulcke MH, Mazzara M, Ben E, Patak A (2012) GMOMETHODS: the European Union database of reference methods for GMO analysis. J AOAC Int 95(6):1713-1719

8. Briza J, Pavingerova D, Vlasak J, Niedermeierova H (2013) Norway spruce (Picea abies) genetic transformation with modified Cry $3 A$ gene of Bacillus thuringiensis. Acta Biochim Pol 60(3):395-400

9. Broeders S, Barbau-Piednoir E, Vandermassen E, Debode F, Mazzara M, Roosens N (2013) New SYBR ${ }^{\circledR}$ Green methods targeting promoter sequences used for screening of several GM events pending for authorisation in Europe. Eur Food Res Technol 236(3):537-547

10. Broeders S, Fraiture MA, Vandermassen E, Delvoye M, Barbau-Piednoir E, Lievens A, Roosens N (2015) New qualitative trait-specific SYBR ${ }^{\circledR}$ Green qPCR methods to expand the panel of GMO screening methods used in the CoSYPS. Eur Food Res Technol 241(2):275-287

11. Broeders S, Huber I, Grohmann L, Berben G, Taverniers I, Mazzara M, Roosens N, Morisset D (2014) Guidelines for validation of qualitative real-time PCR methods. Trends Food Sci Technol $37(2): 115-126$

12. CEN (2014) NPR-CEN/TS 16707:2014 en. 2014-06. Foodstuffs-methods of analysis for the detection of genetically modified organisms and derived products-Polymerase chain reaction (PCR) based screening strategies. 20 p. ISBN 9780580837326

13. Cottenet G, Blancpain C, Sonnard V, Chuah PF (2013) Development and validation of a multiplex real-time PCR method to simultaneously detect 47 targets for the identification of genetically modified organisms. Anal Bioanal Chem 405(21):6831-6844

14. Debode F, Janssen E, Berben G (2013) Development of 10 new screening PCR assays for GMO detection targeting promoters (pFMV, pNOS, pSSuAra, pTA29, pUbi, pRice actin) and terminators (t35S, tE9, tOCS, tg7). Eur Food Res Technol 236(4):659-669

15. Dinon AZ, Prins TW, van Dijk JP, Arisi ACM, Scholtens IMJ, Kok EJ (2011) Development and validation of real-time PCR screening methods for detection of cry $1 A .105$ and cry $2 A b 2$ genes in genetically modified organisms. Anal Bioanal Chem 400(5):1433-1442

16. Dong Y, Du SS, Zhang J, Yang M, Wang J (2015) Differential expression of dual Bt genes in transgene poplar Juba (Populus deltoides cv. 'Juba') transformed by two different transformation vectors. Can J For Res 45(1):60-67

17. European Commission (2011) Regulation (EU) No 619/2011 of 24 June 2011 laying down the methods of sampling and analysis for the official control of feed as regards presence of genetically modified material for which an authorisation procedure is pending or the authorisation of which has expired. Off J L 166:7 
18. European Commission (2012) Implementing Decision 2012/69/ EU of 3 February 2012 amending Decisions 2007/305/EC, 2007/306/EC and 2007/307/EC as regards the tolerance period for traces of Ms1xRf1 (ACS-BNØØ4-7xACS-BNØØ1-4) hybrid oilseed rape, Ms1xRf2 (ACS- BNØØ4-7xACS-BNØØ2-5) hybrid oilseed rape and Topas 19/2 (ACS-BNØØ7-1) oilseed rape, as well as of their derived products (notified under document C(2012) 518). Off J L34. 3 p

19. European Commission (2016) EU Register of authorised GMOs, http://ec.europa.eu/food/dyna/gm_register/index_en.cfm. Accessed 16 March 10

20. Fraiture MA, Herman P, Taverniers I, De Loose M, Deforce D, Roosens NH (2015) Current and new approaches in GMO detection: challenges and solutions. Biomed Res Int 2015:392872-392872

21. Grohmann L, Brunen-Nieweler C, Nemeth A, Waiblinger HU (2009) Collaborative trial validation studies of real-time PCR-based GMO screening methods for detection of the bar gene and the ctp2-cp4epsps construct. J Agric Food Chem 57(19):8913-8920

22. Grohmann L, Reiting R, Made D, Uhlig S, Simon K, Frost K, Randhawa GJ, Zur K (2015) Collaborative trial validation of crylAb/Ac and Pubi-cry TaqMan-based real-time PCR assays for detection of DNA derived from genetically modified Bt plant products. Accredit Qual Assur 20(2):85-96

23. Guo W-C, Wang Z-A, Luo X-L, Jin X, Chang J, He J, Tu E-X, Tian Y-C, Si H-J, Wu J-H (2016) Development of selectable marker-free transgenic potato plants expressing cry3A against the Colorado potato beetle (Leptinotarsa decemlineata Say). Pest Manag Sci 72(3):497-504

24. ISAAA's GM Approval Database. http://www.isaaa.org/gmapprovaldatabase/. Accessed 16 March 2010

25. JRC-ENGL. (2015). Definition of minimum performance requirements for analytical methods of GMO testing. JRC95544. $24 \mathrm{p}$

26. Kamenova I, Batchvarova R, Flasinski S, Dimitrova L, Christova P, Slavov S, Atanassov A, Kalushkov P, Kaniewski W (2008) Transgenic resistance of Bulgarian potato cultivars to the Colorado potato beetle based on Bt technology. Agron Sustain Dev 28(4):481-488

27. Lee J-H, Shin K-S, Suh S-C, Rhim S-L, Lee Y-H, Lim M-H, Woo H-J, Qin Y, Cho H-S (2013) CryIIIA toxin gene expression in transgenic rice confers resistance to rice water weevil. Plant Cell, Tissue Organ Cult 115(2):243-252

28. Li F, Yan W, Long LK, Qi X, Li C, Zhang S (2014) Development and application of loop-mediated isothermal amplification assays for rapid visual detection of $c r y 2 A b$ and $c r y 3 A$ genes in genetically-modified crops. Int J Mol Sci 15(9):15109-15121

29. Liang CJ, van Dijk JP, Scholtens IMJ, Staats M, Prins TW, Voorhuijzen MM, da Silva AM, Arisi ACM, den Dunnen JT, Kok EJ (2014) Detecting authorized and unauthorized genetically modified organisms containing vip3A by real-time PCR and nextgeneration sequencing. Anal Bioanal Chem 406(11):2603-2611

30. Mbella EGM, Lievens A, Barbau-Piednoir E, Sneyers M, Leunda-Casi A, Roosens N, Van den Bulcke M (2011) SYBR ${ }^{\circledR}$
Green qPCR methods for detection of endogenous reference genes in commodity crops: a step ahead in combinatory screening of genetically modified crops in food and feed products. Eur Food Res Technol 232(3):485-496

31. Mi X, Ji X, Yang J, Liang L, Si H, Wu J, Zhang N, Wang D (2015) Transgenic potato plants expressing cry $3 A$ gene confer resistance to Colorado potato beetle. CR Biol 338(7):443-450

32. Mostafa MAM, Vlasak J, Sehnal F (2013) Activities of modified Cry3A-type toxins on the red flour beetle, Tribolium castaneum (Herbst). J Appl Entomol 137(9):684-692

33. Murray MG, Thompson WF (1980) Rapid isolation of high molecular weight plant DNA. Nucleic Acids Res 8(19):4321-4326

34. Querci M, Van den Bulcke M, Zel J, Van den Eede G, Broll H (2010) New approaches in GMO detection. Anal Bioanal Chem 396(6):1991-2002

35. Ren Y, Dong Y, Zhang J, Qiu T, Yang M (2015) Genetic transformation and expression detection of tobacco by using a multigene plant transformation vector. J Animal Plant Sci 25(3):13-21

36. Rosa SF, Gatto F, Angers-Loustau A, Petrillo M, Kreysa J, Querci M (2016) Development and applicability of a ready-touse PCR system for GMO screening. Food Chem 201:110-119

37. Scholtens IMJ, Laurensse E, Molenaar B, Zaaijer S, Gaballo H, Boleij P, Bak A, Kok EJ (2013) Practical experiences with an extended screening strategy for genetically modified organisms (GMOs) in real-life samples. J Agric Food Chem 61(38):9097-9109

38. Sievers F, Wilm A, Dineen D, Gibson TJ, Karplus K, Li WZ, Lopez R, McWilliam H, Remmert M, Soding J, Thompson JD, Higgins DG (2011) Fast, scalable generation of high-quality protein multiple sequence alignments using Clustal Omega. Mol Syst Biol 7:539

39. Smith DS, Maxwell PW, De Boer SH (2004) Method for the detection of synthetic cry $3 A$ in transgenic potatoes. J Agric Food Chem 52(4):809-815

40. Sutton DW, Havstad PK, Kemp JD (1992) Synthetic cryIIIA gene from Bacillus thuringiensis improved for high expression in plants. Transgenic Res 1(5):228-236

41. Tohidfar M, Zare N, Jouzani GS, Eftekhari SM (2013) Agrobacterium-mediated transformation of alfalfa (Medicago sativa) using a synthetic cry $3 a$ gene to enhance resistance against alfalfa weevil. Plant Cell, Tissue Organ Cult 113(2):227-235

42. Van den Bulcke M, Lievens A, Barbau-Piednoir E, Mbongolo Mbella G, Roosens N, Sneyers M, Casi AL (2010) A theoretical introduction to "Combinatory SYBR ${ }^{\circledR}$ Green qPCR Screening", a matrix-based approach for the detection of materials derived from genetically modified plants. Anal Bioanal Chem 396(6):2113-2123

43. Waiblinger HU, Grohmann L, Mankertz J, Engelbert D, Pietsch $\mathrm{K}$ (2010) A practical approach to screen for authorised and unauthorised genetically modified plants. Anal Bioanal Chem 396(6):2065-2072 